\title{
Constipação intestinal crônica inespecífica do lactente: um problema a ser explorado
}

\author{
Breastfed infants with chronic idiopathic constipation: a problem to be studied
}

\author{
Dorina Barbieri*
}

$\mathbf{N}_{\mathrm{a}}$ duplo significado: indica resfriado, obstrução nasal, ou indica prisão de ventre. Por esta razão, quando este termo é empregado em gastroenterologia, deve ser seguido do termo intestinal. Em português, o termo "obstipação" tem significado único de prisão de ventre e, portanto, pode ser usado sem a complementação da palavra "intestinal", porém ele é pouco usado pelos médicos brasileiros.

O uso do termo constipação para indicar o estado mórbido de redução de evacuação é um legado da língua inglesa, e que se fixou na linguagem médica brasileira.

Este preâmbulo serve de introdução para alguns comentários a respeito do artigo "Constipação em lactentes: influência do tipo de aleitamento e da ingestão de fibra alimentar" de autoria de Aguirre e col., publicado neste número do Jornal de Pediatria.

De acordo com DiLorenzo", o termo "constipation" indica um sintoma, e não uma doença, pois acompanha várias situações clínicas, como hipotiroidismo, malformações anorretais, doença de Hirschsprung, etc. Entretanto, pode ocorrer um quadro de constipação intestinal de evolução crônica sem que se consiga estabelecer uma causa orgânica, metabólica ou endócrina, e este quadro recebe o nome de constipação intestinal crônica inespecífica (CICI). Os autores do trabalho em foco não utilizam esta nomenclatura, mas, pela seleção dos pacientes, conclui-se que as crianças, nas quais foi observado hábito intestinal do tipo constipado, pertenciam a essa categoria de constipação intestinal crônica inespecífica.

Deste trabalho serão comentados dois pontos: a valorização do exame visual das fezes e do padrão evacuante evolutivo com a idade, e a ação protetora do leite humano em relação à CICI.

* Livre Docente em Pediatria pela Faculdade de Medicina da Universidade de São Paulo.

\section{Aspectos morfológicos fecais e padrão evacuante evolu- tivo com a idade}

O exame morfológico visual das fezes realizado pela mãe, em confronto com um quadro ilustrando as diferentes formas de fezes, mostrou que é possível estabelecer um diagnóstico de constipação intestinal quando associado à informação de alterações sensoriais durante o ato evacuativo.

Vários autores ${ }^{2,3}$ já empregaram tal método, inclusive para outras doenças. Furukava ${ }^{3}$, no Japão, elaborou um atlas com essa finalidade. Na falta de uma tabela ilustrativa, o pediatra poderá substituí-la pela visão direta das fezes, solicitando à mãe que traga as fezes para ele mesmo analisar visualmente e poder, também, nos casos de referência à sangramento, quebrar a massa fecal e verificar se o sangue é só superficial, indicando sangramento baixo, ou se está dentro da massa, indicando sangramento alto.

$\mathrm{O}$ aspecto cibaloso das fezes ocorre quando o colo todo se apresenta espástico, e as fezes ficam retidas nas saculações do colo e vão adquirindo aspecto globoso, e depois se tornam endurecidas, caracterizando a constipação do tipo espástica, diferente da constipação por dificuldade de via de saída, na qual as fezes ficam retidas no sigmóide e no reto, e formam grossos cilindros de expulsão difícil, e que podem entupir o vaso sanitário.

Vale lembrar que as fezes são o marcador natural da função digestiva, e muitas informações importantes são perdidas pela omissão de seu exame macro e microscópico.

Além do aspecto das fezes, deve ser levado em conta o padrão evacuativo normal das crianças que, como foi citado no trabalho, sofre modificações desde o nascimento até os períodos etários mais avançados. Excelente revisão de Weaver ${ }^{4}$ mostra que, de um modo geral, nos primeiros 14 dias de vida, a criança evacua entre duas a sete vezes por dia. No $5^{\circ}$ mês, essa freqüência se reduz para uma a três vezes; ao redor do $2^{\circ}$ ano essa freqüência se estabiliza em uma vez e, no período senil, pode a exoneração ocorrer em dias alternados. Mas, evidentemente, o padrão normal deve ser considerado individualmente. A mudança de consistên- 
cia das fezes de líquida para firmes, assim como a redução no número de evacuações é resultado do amadurecimento das funções digestivo-absortivas do intestino, assim como sua atividade motora. Essa tendência natural de redução de frequiência de exoneração com a idade é fator predisponente à instalação de constipação intestinal quando o indivíduo é submetido a erros alimentares, ou ao enfrentar situações de impacto biopsicossocial de efeito somatizante obstipante.

\section{A ação protetora do leite humano}

A presença de fezes líquidas ou moles na criança que recebe amamentação exclusiva é fato bem conhecido e já devidamente esclarecido.

Assim, de acordo com o trabalho de Quinlan e col. ${ }^{5}$, a dosagem de ácidos graxos saponificados ligados ao cálcio, formando complexos insolúveis nas fezes de criança com aleitamento artificial, apresentavam valores muito altos e diretamente relacionados com o grau de dureza dessas fezes. Nas crianças com amamentação natural, esses ácidos graxos saponificados eram ausentes ou com valores muito baixos, não sendo encontrados complexos insolúveis, fato que pode explicar a consistência mole das fezes dessas crianças. A digestão e absorção das gorduras do leite humano são quase totais em razão da existência, no leite humano, da lipase, estimulada pelos sais biliares e pela constituição das gotículas de gorduras, ricas em colesterol e ácidos graxos de cadeia longa polinsaturados.

Este trabalho ${ }^{5}$ comprovou, também, uma alta concentração de carboidratos complexos nas fezes dessas crianças, nas quais um terço do peso seco fecal era constituído por carboidratos. O efeito osmótico destes carboidratos deve ter contribuído para o aumento de água luminal e, conseqüentemente, para a formação de fezes fluidas.

Entretanto, no trabalho em foco, $4,5 \%$ das crianças menores de 6 meses e com amamentação exclusiva apresentaram constipação intestinal. Esse valor, embora sem significado estatístico, é importante sob ponto de vista clínico, pois essas crianças representam uma minoria não protegida pelo leite humano. Por quê?

\section{Comentários finais}

A constipação intestinal crônica inespecífica é resultante da ação de múltiplos fatores ainda não totalmente estabelecidos, mas é indubitável que um deles é a predisposição individual para sua instalação. Isso ficou claro pelo índice de 4,5\% de crianças menores de 6 meses com amamentação e com constipação intestinal, e pela presença de 31 crianças com idade entre 6 a 24 meses que se apresentavam obstipadas, embora estivessem ingerindo quantidades de fibra igual ao grupo não obstipado.

A capacidade absortiva do colo é muito variável entre os indivíduos. Devroede e Soffié ${ }^{6}$, em trabalhos de perfusão do colo de adultos com constipação intestinal, demonstraram que nestes últimos essa capacidade era significativamente maior do que nos do grupo controle.

Pereira e Barbieri ${ }^{7}$ também observaram, indiretamente, essa possibilidade, pois, realizando provas de absorção de açúcares através de curva glicêmica, em crianças obstipadas, acharam que 38\% delas eram não absorvedoras de sacarose, e $82 \%$ não absorvedoras de lactose. Possivelmente, nestas crianças, o excesso de água luminal decorrente da pressão osmótica exercida pelos açúcares não absorvidos foi transportado para o meio interno pela mucosa cólica graças à sua alta capacidade absortiva. Evidentemente, não se pode aceitar que, obrigatoriamente, este fator de predisposição seja esta capacidade absortiva aumentada, mas poderá ser qualquer outro fator ligado ou às características diferenciadas da atividade motora, ou vinculado a alguns entero-hormônios com ação sobre a motilidade intestinal. Esses fatores podem ocorrer apenas em determinados indivíduos, que serão aqueles que desenvolverão a obstipação.

A expectativa é de que futuras pesquisas elucidarão essas dúvidas, auxiliando no tratamento desta entidade.

\section{Referências bibliográficas}

1. Di Lorenzo C. Constipation. In: Hyman PE, editor. Pediatric Gastrointestinal Motility Disorders. New York (NY): Academic Professional Information Services; 1994.p.129-43.

2. Weaver LT, Ewing G, Taylor LC. The bowel habit of milk-fed infants. J Pediatr Gastroenterol Nutr 1988;7:568-71.

3. Furukawa M. A chart of infant and children's stool. Tokyo: Kanehara Shuppan; 1983.

4. Weaver LT. Bowel habit from birth to old age. J Pediatr Gastroenterol Nutr 1988;7:637-40.

5. Quilan PT, Lockton S, Irwin J, Lucas AL. The relationship between stool hardness and stool composition in breast- and formula-fed infants. J Pediatr Gastroenterol Nutr 1995;20:81-90.

6. Devroede G, Soffié M. Colonic absorption in idiopathic constipation. Gastroenterology 1973;64:552-61

7. Pereira Filho OD, Barbieri D. Considerações etiopatogênicas sobre a constipação crônica na infância. Comportamento das provas de absorção de dissacarídeos. Pediatria (São Paulo) 1984;6:13-7. 